\section{Overfeeding: A Rare Cause of Failure to Wean Identified via Indirect Calorimetry}

\section{Sir,}

Acute overfeeding-related problems are seldom reported in literature when compared to the effects of underfeeding. A 41year female patient, on chronic antipsychotic medications (tab Olanzapine at $20 \mathrm{mg} /$ day), presented do the intensive care unit (ICU) with severe shortness of breath and decreased responsiveness. She had very poor oral intake for the last 3 months. On admission, her height was $160 \mathrm{~cm}$, weight was $50 \mathrm{~kg}$ (ideal body weight $-55 \mathrm{~kg}$ ), and body mass index (BMI), $19.5 \mathrm{~kg} / \mathrm{m}^{2}$. Her serum albumin on admission was $2.0 \mathrm{~g} / \mathrm{dL}$ with mild anemia ( hemoglobin - $8.5 \mathrm{~g} / \mathrm{dL}$ ). The initial estimated caloric requirement was $1600 \mathrm{kcal} /$ day, proteins $-56 \mathrm{~g}$, to reach target at $5^{\text {th }}$ day. Initial feeding was started at $10 \mathrm{kcal} / \mathrm{kg} /$ day with $0.5 \mathrm{~g} / \mathrm{kg}$ /day of protein with close watch on potassium and phosphorous, as part of the dreaded "refeeding syndrome," and she slowly progressed to goal overfive days.

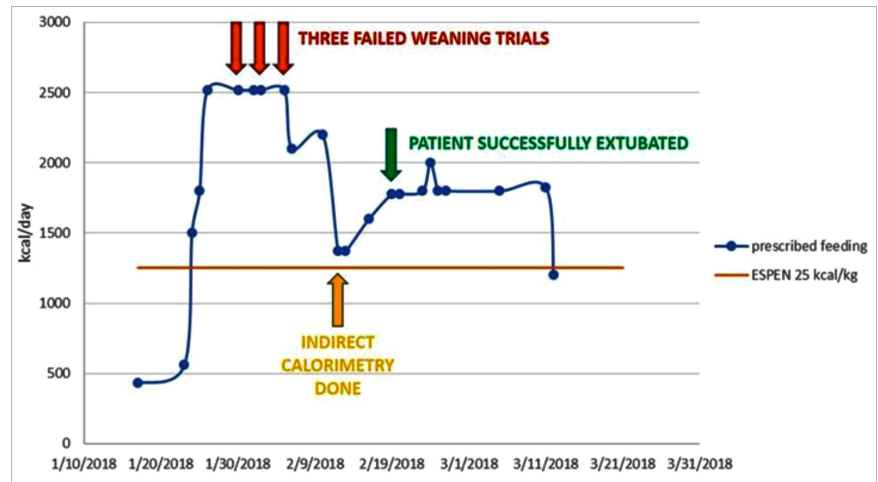

Figure1: Graphical representation of course of events.

On the second hospital day, the patient was intubated due to acute respiratory distress syndrome (ARDS). All daily spontaneous breathing trials failed due to increase in the minute ventilation with characteristic rise in the rapid shallow breathing index to greater than 120 . Thyroid, cortisol, and electrolytes levels were normal. However, the end tidal carbon dioxide levels did not change. There was no intolerance to enteral feeding. For the next one week, there was a failure to wean, which was attributed to critical illness polyneuropathy. Due to limb weakness and unexplained difficulty in weaning from mechanical ventilation, reassessment of total caloric intake via indirect calorimetry on the Carescape R860 ventilator was done. The indirect calorimeter measured an energy expenditure of $1505 \mathrm{kcal} /$ day. Hence, the enteral feeding calories provided were readjusted to $1375 \mathrm{kcal} /$ day. The patient was successfully weaned off from the ventilator three days after adjustment of feedingand a total of 30 days on mechanical ventilation (Figure 1).
Indirect calorimetry is the gold standard for energy assessment for critically ill patients. ${ }^{1,2}$ In spite of this, the use of indirect calorimetry has been very poor throughout the world and very few centres in the world use this monitoring on a regular basis. Psychotropic medications may have profound alterations, both on metabolism and energy expenditure. ${ }^{3,4}$ However, to date, there have been no published guidelines to assist clinicians in choosing appropriate prediction equations to estimate energy expenditure in persons taking atypical antipsychotic medications. ${ }^{5}$

Overfeeding medically compromised patients can exacerbate respiratory failure by increasing physiological stress; and thus, may prolong days on the ventilator by increasing carbon dioxide production, which increases the amount of ventilation necessary to maintain a steady state of arterial blood gases. In this specific case, $2500 \mathrm{kcal} /$ day of enteral feeding was prescribed (after adjustment for stress of ARDS) as per the ESPEN-guidelines, which recommend $25 \mathrm{kcal} /$ day. This may have inadvertently led to overfeeding, resulting in difficulty in weaning. Guided by indirect calorimetry, the total caloric support was reduced, and the patient was then successfully weaned off from the ventilator.

This case illustrates the importance of personalising nutrition in critically ill patients, which can be done scientifically by using the indirect calorimeter.

\section{CONFLICT OF INTEREST:}

The authors declared no conflict of interest.

\section{AUTHORS' CONTRIBUTION:}

SS: Data acquisition, analysis, and drafting of manuscript. AC: Analysis and data acquisition.

\section{REFERENCES}

1. Rattanachaiwong $S$, Singer P. Should we calculate or measure energy expenditure? Practical aspects in the ICU. Nutrition 2018; 55-6:71-75. doi:10.1016/j.nut.2018.05.001.

2. Preiser JC, van Zanten AR, Berger MM, Biolo G, Casaer MP, Doig GS, et al. Metabolic and nutritional support of critically ill patients: Consensus and controversies. Critical care 2015; 19(1):35. doi: 10.1186/s13054-015-0737-8.

3. Cuerda C, Velasco C, Merchan-Naranjo J, Garcia-Peris P, Arango $C$. The effects of second-generation antipsychotics on food intake, resting energy expenditure and physical activity. European J Clin Nutrition 2014; 68(2):146. doi: 10.1038/ ejcn.2013.253.

4. Virkkunen M, Wahlbeck K, Rissanen A, Naukkarinen $H$, Franssila-Kallunki A. Decrease of energy expenditure causes weight increase in olanzapine treatment-a case study. Pharmacopsychiatry 2002; 35(03):124-6. doi: 10.1055/ s-2002-31521.

5. Sharpe JK, Byrne NM, Stedman TJ, Hills AP. Resting energy expenditure is lower than predicted in people taking atypical antipsychotic medication. J Am Diet Assoc 2005; 105(4): 612-5. doi: 10.1016/j.jada.2005.01.005. 
Sanjith Saseedharan and Annapurna Chiluka

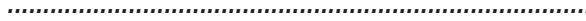

Department of Critical Care, S.L. Raheja Hospital, Mahim, Mumbai

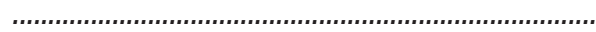

Correspondence to: Dr. Sanjith Saseedharan, Department of
Critical Care, S.L. Raheja Hospital, Mahim, Mumbai, India E-mail: docsanjith@rediffmail.com

...................................................................

Received: April 07, 2020; Revised: April 08, 2020; Accepted: April 09, 2020

DOI: https://doi.org/10.29271/jcpsp.2021.04.489

$\bullet \bullet \bullet \bullet \bullet \bullet \bullet \bullet \bullet$ 